\title{
STRATEGI PEMASARAN MANGGA KLONAL 21 DI KABUPATEN PASURUAN
}

\author{
Nur Yunita Puspitasari ${ }^{1}$, Wahyu Santoso $^{2}$, Hamidah Hendrarini ${ }^{3}$ \\ ${ }^{1}$ Mahasiswa Program Studi Agribisnis Fakultas Pertanian UPN "Veteran" Jawa Timur \\ ${ }^{2,3}$ Program Studi Agribisnis Fakultas Pertanian UPN "Veteran” Jawa Timur \\ e-mail:nuryunita1802@gmail.com
}

\begin{abstract}
ABSTRAK
Tujuan penelitian ini guna mengetahui strategi komunikasi pemasaran yang tepat pada sentra budidaya mangga klonal 21. Metode pengumpulan data menggunakan deskripstif kuantitatif dengan tahap observasi, wawancara dan penggunaan kuisioner SWOT kepada petani mangga klonal 21 yang digunakan untuk menentukan strategi yan tepat dalam memasarkan mangga klonal 21 berdasarkan faktor internal dan eksternal. Teknik pengambilan sampel menggunakan metode purposive sampling dimana menggunakan pengambilan sampel non random dengan jumlah populasi 120 orang petani yang dipergunakan sampel sebanyak 50 petani dikarenakan masih tergabung dalam satu gapoktan. Strategi yang tepat sesuai SWOT berupa melakukan diversifikasi produk guna menaikkan penjualan revenue secara signifikan. Strategi diversifikasi yang dapat diterapkan pada pemasaran yakni mengembangkan produk olahan berbahan dasar mangga klonal 21 dan menggunakan media sosial sebagai media pemasaran guna menarik minat beli konsumen saat berada di luar Kabupaten Pasuruan. Matriks QSPM digunakan untuk mengetahui alternatif strategi yang akan digunakan. Alternatif strategi tersebut berupa melakukan pengembangan off season guna memenuhi permintaan pasar dan pengembangan produk olahan dengan mengedepankan kualitas SDM berupa penggunaan teknologi guna memnunjang kualitas dan kuantitas mangga klonal 21.
\end{abstract}

Kata kunci : Strategi komunikasi pemasaran, SWOT, QSPM

\begin{abstract}
The purpose of this study was to determine the right marketing communication strategy at the clonal 21 mango cultivation center. The data collection method used quantitative descriptive with the stages of observation, interviews and the use of SWOT questionnaires to clonal 21 mango farmers which was used to determine the right strategy in marketing clonal 21 mango based on internal and external factors. The sampling technique used was purposive sampling method which used non-random sampling with a population of 120 farmers who used a sample of 50 farmers because they were still members of one Gapoktan. The right strategy according to SWOT is to diversify products to increase revenue sales significantly. Diversification strategies that can be applied to marketing are developing processed products made from clonal 21 mangoes and using social media as a marketing medium to attract consumer buying interest while outside Pasuruan Regency. The QSPM matrix is used to find out the alternative strategies to be used. The alternative strategy is conducting off season development to meet market demand and developing processed products by prioritizing the quality of human resources in the form of using technology to support the quality and quantity of clonal mangoes.
\end{abstract}


Keywords : Marketing communication strategy, SWOT, QSPM

\section{PENDAHULUAN}

Mangga tergolong komoditas buah sub tropis dapat hidup di dataran rendah dan mudah dilakukan pembudidayaan. Tanaman mangga ialah tanaman buah tahunan berupa pohon yang berasal dari negara India (Oktavianto et al., 2015). Kabupaten Pasuruan memiliki berbagai macam varietas mangga, tetapi yang lebih dikenal masyarakat luas yakni mangga klonal 21. Terdapat tiga sentra pengembangan mangga klonal 21 yakni Rembang, Sukorejo, dan Wonorejo. Diantara ketiga kecamatan tersebut, Kecamatan Rembang menjadi sentral pembudidayaan mangga klonal 21 secara intensif. Mangga (Mangifera indica L) merupakan salah satu komoditas hortikultura unggulan di Indonesia. Selain karena harga yang terjangkau, buah mangga memiliki nilai ekonomi tinggi dan merupakan bahan makanan penting setelah pisang bagi masyarakat di daerah beriklim tropis juga menjadi salah satu faktor permintaan dan produksi mangga terus bertambah setiap tahun (Azizah et al., 2019). Tekstur yang dimiliki oleh mangga klonal 21 yakni sedang dengan kekuatan aroma yag lemah dibanding aroma mangga varietas lain yang terkesan lebih kuat. Rasa yang dominan dalam mangga klonal 21 ini manis tanpa ada rasa asam sehingga cocok bagi pecinta buah bercitarasa manis dibandingkan dengan varietas mangga lain. Tingkat produksi mangga klonal 21 mencapai $136 \mathrm{~kg} /$ tahun sehingga dapat memenuhi permintaan konsumen.

Strategi pemasaran adalah salah satu cara memenangkan keunggulan bersaing yang berkesinambungan baik itu untuk perusahaan yang memproduksi barang atau jasa (Wibowo et al., 2015). Perusahaan atau bidang usaha dituntut melakukan inovasi menciptakan transparansi baru guna mencapai tujuan laba maksimum yang diperoleh dari penjualan. Menurut (Wira'artha et al., 2017) pengambilan keputusan seperti ini, haruslah berhatihati dalam mengambil sebuah keputusan yang berkaitan dengan strategi pemasaran.

Mangga klonal 21 memiliki keunikan tersendiri dibanding dengan mangga varietas lain yakni cara pengkonsumsiannya yang dapat langsung dimakan dengan sendok. Pemetikan buah dapat dilakukan pada saat matang pohon kemudian permukaan tengah buah digoreskan melingkar seperti membuka buah alpukat guna menjadi dua bagian sehingga daging buah terbuka dan langsung dinikmati dengan menggunakan sendok untuk mengambil daging buah. Permasalahan yang terdapat dalam pemasaran mangga klonal 21 yakni pemasaran yang hanya di kota besar karena kurangnya informasi dan adanya pedagang curang mengatasnamakan mangga klonal 21 . Cita rasa merupakan atribut makanan yang meliputi penampakan, bau, rasa, tekstur, dan suhu (Asrina et al, 2017). Mangga klonal 21 memiliki cita rasa yang berbeda jika dibandingkan dengan varietas lain, sehingga menjadi keunikan tersendiri dari segi rasa dan tekstur yang dimiliki.

$$
\text { Berdasarkan latar belakang }
$$
tersebut, maka dapat diturunkan beberapa tujuan penelitian, diantaranya adalah identifikasi faktor internal dan eksternal, dan analisis strategi pemasaran yang tepat untuk menjual buah mangga klonal 21. Penelitian ini menjadi penting dikarenakan penggunaan strategi pemasaran yang tepat dapat memperluas pasar dan dapat 
menghindari pemalsuan produk mangga sejenis yang mengatasnamakan mangga klonal 21. Strategi pemasaran dalam dunia bisnis jelas memiliki peran yang sangat penting dalam sebuah proses pembentukan kesadaran dan edukasi konsumen (Mc Leod Raymond, 2017). Strategi komunikasi pemasaran yang tepat dapat membantu petani mangga klonal 21 dalam mengembangkan pemasaran yang lebih luas dengan bantuan informasi baik dari media massa atau media cetak. Penggunaan strategi komunikasi pemasaran yang sesuai dapat meningkatkan penjualan mangga klonal 21 secara pesat dan merata melalui promosi di media sosial. Menurut Octaviani et al.,(2018) iklan sangat penting bagi perusahaan produk maupun jasa, tanpa adanya iklan, sebaik dan sehebat apapun produk/jasa yang dihasilkan, jika tidak di komunikasikan ke masyarakat tentang keberadaannya, maka hal itu akan sia-sia. Strategi komunikasi pemasaran yang tepat juga membantu konsumen dalam memilih mangga klonal 21 asli yang dijual oleh APMG 21 dan dapat menghindari pemalsuan mangga klonal 21 dengan menggunakan varietas mangga lain yang dijual oleh oknum pedagang curang.

\section{METODOLOGI PENELITIAN}

Pengambilan data penelitian dilakukan pada Kecamatan Rembang, Pasuruan, Jawa Timur sebagai sentral budidaya tanaman mangga klonal 21 secara intensif. Waktu penelitian pada bulan Desember 2020 - Januari 2021. Penelitian ini menggunakan beberapa metode untuk mengumpulkan data yang dibutuhkan, antara lain kuesioner, dokumentasi, dan wawancara. Penelitian ini menggunakan data primer dan data sekunder (Mukhsin et al, 2017).
Data primer yang digunakan berupa hasil observasi, wawancara dengan beberapa pengisian kuisioner oleh responden. Data sekunder yang digunakan dana penelitian berupa data dari Dinas Pertanian Kabupaten Pasuruan dan Dinas Pertanian Provinsi Jawa Timur serta literature lainnya.

Penelitian ini bersifat kuantitatif dimana mengolah data yang diperoleh guna menentukan bobot dan rating yang dapat menghasilkan strategi komunikasi yang tepat dalam pemasaran mangga klonal 21.

Teknik penelitian survei digunakan untuk melakukan eksplorasi dan analisis secara intensif terhadap suatu fenomena dengan menggunakan data dari sejumlah sampel berupa orang menggunakan kuesioner (Utami \& Firdaus, 2018). Metode dalam penelitian ini adalah metode kualitatif, yang digunakan untuk mendeskripsikan tanggapan responden terhadap subjek berdasarkan kuesioner yang diberikan. Teknik pengumpulan data yang digunakan dalam penelitian ini adalah dengan observasi langsung mengenai kegiatan komunikasi pemasaran yang terjadi di lokasi penelitian, wawancara mendalam kepada informan (dalam hal ini adalah objek penelitian) (Prayogo, 2015).

Menurut Sugiyono (2011:61) menyatakan bahwa sampling purposive adalah teknik penentuan sampel dengan pertimbangan tertentu. Data yang digunakan yakni data primer diperoleh dari hasil observasi, wawancara dan pengisian kuisioner serta data sekunder berasal dari Dinas Pertanian Kabupaten Pasuruan. Jumlah sampel petani yang digunakan dalam penelitian sebanyak 50 orang petani mangga klonal 21 , Alasan penggunaan sampel sebanyak 50 orang dimana mayoritas hasil wawancara memiliki jawaban sama dikarenakan 120 orang yang 
merupakan populasi tergabung dalam Gapoktan Tani Makmur Sentosa. Metode pengambilan sampel dalam penelitian ini menggunakan teknik Purposive sampling dengan penentuan kriteria petani yang tergabung dalam Gapoktan Tani makmur Sentosa, memilik lahan minimal 0,5 ha dengan jumlah pohon minimal 50 pohon mangga klonal 21. Tujuan penggunaan purposive sampling dimana ingin memberikan sumbangsih strategi pemasaran yang baik dan dapat direalisasikan oleh petani yang memiliki permasalahan yang sama pada lingkup Gapoktan Tani Makmur Sentosa.

Purposive sampel yaitu sampel yang dilakukan dengan cara mengambil subyek bukan didasarkan atas strata, random atau daerah tetapi didasarkan atas adanya tujuan tertentu (Heridiansyah, 2012). Definisi operasional variabel merupakan bagian yang mendefinisikan sebuah konsep atau variabel agar dapat diukur, dengan cara melihat pada dimensi (indikator) dari suatu konsep atau variabel (Noor Juliansyah, 2012).

Definisi operasioanl variabel mencakup mangga klonal 21 menjadi produk unggulan Kabupaten Pasuruan dan menjadi varietas mangga yang jarang dijumpai, lokasi startegis dengan agroklimat yang sesuai menjadi keberhasilan dalam budidaya, SDM terampil menjadi penunjang keberhasilan melakukan budidaya, harga yang kompetitif menggambarkan kualitas buah yang mampu bersaing, APMG aktif dapat menjembatanui kebutuhan kelompok tani, kualitas buah yang baik menjadi ciri khas yang menonjol bagi konsumen, keunikan panen yang hanya 6 bulan menjadi keunikan tersendiri bagi mangga klonal 21, skala usaha kecil dengan modal terbatas sehingga pemasaran yang belum meluas.
Kurangnya pemasaran online menjadi kelemahan dan keteerbatasan petani, teknologi pasca panen yang belum optimal dapat memeprmudah pembusukan menyebabkan kerugian, lembaga perkreditan mulai bermunculan sehingga petani melakukan peminjaman modal, permintaan pasar yang melampaui batas menjadi ancaman jika stok menipis dan dikhawatirkan konsumen berpindah pada varietas lain, dan kondisi ekonomi masa pandemi mempengaruhi pembelian mangga klonal 21.

Teknik analisis dalam pemecahan faktor internal dan eskternal menggunakan SWOT guna menentukan srategi komunikasi pemasaran yang tepat. Matriks SWOT digunakan untuk merumuskan alternatif strategi yang ditampilkan dalam delapan kotak, yaitu dua kolom di bagian atas untuk faktor internal dan dua kolom di bagian kiri untuk faktor eksternal (Amarala et al, 2020). Altrenatif strategi yang digunakan guna menentukan strategi cadangan menggunakan matriks QSPM.

\section{III.HASIL DAN PEMBAHASAN}

Pengembangan mangga klonal 21 dilakukan Pemerintah Kabupaten Pasuruan pada tahun 1994 melalui Program Pembangunan Pertanian Terpadu dengan luas lahan 3.295 ha total pohon sebanyak 337.375 pohon mangga klonal 21. Nama mangga klonal 21 telah dikenal oleh masyarakat luas sejak kemunculannya di media sosial karena keunikan pengkonsumsiannya. Antusias konsumen meningkat karena adanya mangga yang unik sehingga mendulang pendapatan tinggi. Hal ini yang menyebabkan banyaknya pedagang curang yang menjual mangga varietas lain dengan nama mangga klonal 21 yang menyebabkan kerugian bagi petani yang tergabung pada APMG 21. Perumusan strategi komunikasi 
pemasaran dianggap sebagai upaya kedepan jangka panjang guna memutus penipuan yang merugikan kedua belah pihak antara konsumen dan petani. Selain itu juga mempertahankan pasar di tengah persaingan bisnis mangga yang lainnya. Perumusan strategi menggunakan analisis faktor internal dan eksternal sebagai faktor kunci.. Faktor internal dan ekstrenal dapat dilihat pada tabel 1 dan 2 .

Tabel 1.Matriks IFE

\begin{tabular}{|c|c|c|c|c|}
\hline No & Faktor Internal & Bobot & Rating & Skor \\
\hline \multicolumn{5}{|c|}{ Kekuatan } \\
\hline 1. & Produk unggulan Kabupaten Pasuruan & 0.09 & 3.26 & 0.29 \\
\hline 2. & Lokasi pembudidayaan sesuai agroklimat & 0.09 & 3 & 0.27 \\
\hline 3. & SDM petani terampil & 0.09 & 3.16 & 0.28 \\
\hline 4. & Harga mangga lebih kompetitif & 0.1 & 3.5 & 0.355 \\
\hline 5. & Adanya APMG yang aktif & 0.09 & 3.12 & 0.28 \\
\hline 6. & Kualitas buah yang tinggi & 0.09 & 3.16 & 0.28 \\
\hline Tota & Kekuatan & 0.55 & & 1.75 \\
\hline \multicolumn{5}{|c|}{ Kelemahan } \\
\hline 1 & Musim tidak menentu & 0.07 & 2.38 & 0.17 \\
\hline 2 & Skala usaha petani kecil & 0.07 & 2.5 & 0.18 \\
\hline 3 & Kurangnya pemasaran online & 0.08 & 2.7 & 0.22 \\
\hline 4 & Teknologi pasca panen yang terbatas & 0.08 & 2.64 & 0.21 \\
\hline 5 & Modal petani masih rendah & 0.08 & 2.68 & 0.21 \\
\hline 6 & Biaya produksi tinggi & 0.07 & 2.62 & 0.18 \\
\hline \multicolumn{2}{|c|}{ Total Kelemahan } & 0.45 & & 1.17 \\
\hline \multicolumn{2}{|c|}{ Total Faktor Internal } & 1,00 & & 2.92 \\
\hline
\end{tabular}

Tabel 2. Matriks EFE

\begin{tabular}{|c|c|c|c|c|}
\hline No & Faktor Eksternal & Bobot & Rating & Skor \\
\hline \multicolumn{5}{|c|}{ PELUANG } \\
\hline 1. & Tren sosial konsumen & 0.07 & 2.72 & 0.19 \\
\hline 2. & Permintaan konsumen meningkat & 0.08 & 2.9 & 0.23 \\
\hline 3. & Lembaga perkreditan meningkat & 0.08 & 2.88 & 0.23 \\
\hline 4 & Tuntutan pemasaran online masa pandemi & 0.09 & 3.14 & 0.28 \\
\hline 5. & $\begin{array}{l}\text { Kebijakan pemerintah setempat yang } \\
\text { mendukung }\end{array}$ & 0.09 & 3.32 & 0.3 \\
\hline 6. & Buah yang memiliki keunikan & 0.09 & 3.42 & 0.31 \\
\hline \multirow{2}{*}{\multicolumn{5}{|c|}{ Ancaman }} \\
\hline & & & & \\
\hline 1 & Hama dan penyakit & 0.07 & 2.74 & 0.19 \\
\hline 2 & Skala usaha petani kecil & 0.07 & 3.3 & 0.3 \\
\hline 3 & Kurangnya pemasaran online & 0.09 & 3.18 & 0.29 \\
\hline 4 & Teknologi pasca panen yang terbatas & 0.09 & 3.2 & 0.29 \\
\hline 5. & Modal petani masih rendah & 0.08 & 2.86 & 0.23 \\
\hline & Biaya produksi tinggi & 0.08 & 3.02 & 0.25 \\
\hline \multirow{2}{*}{\multicolumn{2}{|c|}{$\begin{array}{l}\text { Total Ancaman } \\
\text { Total Faktor Eksternal }\end{array}$}} & 0.5 & & 1.55 \\
\hline & & 1,00 & & 3.09 \\
\hline
\end{tabular}

Sumber : Data Primer Diolah, 2020

Menurut Suandani et al., (2016)

Faktor eksternal dikumpulkan untuk menganalisis hal-hal yang menyangkut

persoalan ekonomi, sosial, budaya, demografi, teknologi, dan persaingan. Pemasaran mangga klonal 21 memiliki 
total skor internal sebesar 2,92 yang menunjukkan posisi internal usaha budidaya mangga klonal 21 sangat kuat. Total skor yang diperoleh lebih dari 2,5, Skor Bobot total berada diatas nilai 2,5 yang menandakan bahwa kondisi perusahaan secara internal masih sangat kuat (Nur Aziz et al., 2021). Hal ini menunjukkan bahwa perusahaan mampu merespon dengan baik faktor eksternal dengan memanfaatkan peluang yang ada untuk mengatasi ancaman (Mujahid et al., 2018).

Kekuatan utama pemasaran mangga klonal 21 yakni harga mangga lebih kompetitif dimana memperoleh nilai 0,35 dimana harga mangga klonal 21 lebih mahal dibandingkan varietas mangga lain karena memiliki keunikan tersendiri. Kelemahan utama yang dimiliki mangga klonal 21 yakni 0,22 dimana kurangnya pemasaran online yang hanya dikelola oleh beberapa petani yang melek teknologi sehingga menyebabkan mangga klonal 21 belum berkembang lebih luas yang dapat menjangkau seluruh penjuru negeri. Skor total untuk faktor eksternal adalah 3,09 yang lebih tinggi dari skor ratarata 2,5 yang menunjukkan bahwa budidaya mangga klonal 21 dapat menghadapi dan menghindari ancaman serta memanfaatkan peluang. Peluang utama yang dimiliki usaha budidaya mangga klonal 21 yakni produk yang jarang dijumpai memperoleh skor sebesar 0,31 dimana produk mangga klonal 21 hanya ditemui di kabupaten Pasuruan karena menjadi produk ikonik dari kota tersebut sehingga peluang untuk permintaan pasar dikarenakan mangga klonal 21 yang tidak dapat ditemui di daerah lain. Ancaman utama yang mengancam usaha budidaya mangga klonal 21 yakn penipuan yang mengatasnamakan mangga klonal $21 \mathrm{di}$ media online memperoleh skor 0,29 dimana pada indikator ini menjadi ancaman jika pesaing sejenis terus melakukan penipuan dengan menjual mangga varietas lain tetapi diatasnamakan mangga klonal 21.

\section{Analisis Strategi Pemasaran Mangga Klonal 21}

Analisis matriks IE dilakukan untuk mempertajam analisis yang telah dilakukan dengan matriks IFE dan EFE (Sawitri, 2018). Menurut Sugianto et al, (2017) matriks Internal-Eksternal merupakan matriks yang meringkas hasil evaluasi faktor eksternal dan internal yang menempatkan perusahaan pada salah satu kondisi di dalam sembilan sel, dimana tiap-tiap sel merupakan kondisi langkah yang harus ditempuh perusahaan. Berdasarkan perhitungan faktor internal dan ekstrenal dapat diperoleh skor matriks internal eksternal (IE) strategi komunikasi pemasaran mangga klonal 21. Skor matriks IE terdapat pada Tabel 3.

Tabel 3. Matriks IE

\begin{tabular}{cc|cc}
\hline \multicolumn{2}{c}{ IFE } & \multicolumn{2}{c}{ EFE } \\
\hline Kategori & Total Skor & Kategori & Total Skor \\
\hline Kekuatan $(\mathrm{S})$ & 1.763 & Peluang $(\mathrm{O})$ & 1.542 \\
\hline Kelemahan $(\mathrm{W})$ & 1.166 & Ancaman $(\mathrm{T})$ & 1.543 \\
\hline Total $(\mathrm{S}-\mathrm{W})$ & 0.596 & Total $(\mathrm{O}-\mathrm{T})$ & -0.001 \\
\hline \multicolumn{2}{c}{ Sumber: Data Primer Diolah, 2020 }
\end{tabular}




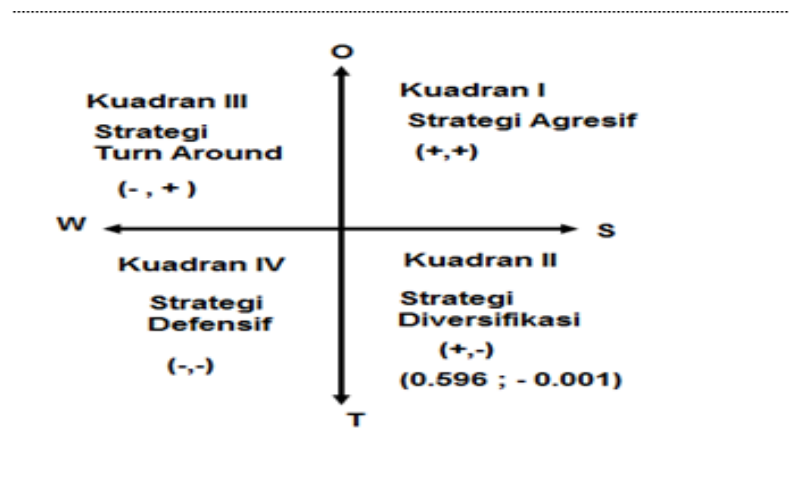

Gambar 1 Diagram Analisis Matriks SWOT

\section{Analisis Matriks SWOT Pemasaran Mangga Klonal 21}

Tabel 4. Analisis Matriks SWOT

Matriks SWOT

\begin{tabular}{l} 
Kekuatan (S) \\
\hline a. Produk unggulan \\
Kabupaten Pasuruan \\
b. Lokasi pembudidayaan \\
sesuai agroklimat \\
c. SDM petani terampil \\
d. Harga mangga lebih \\
kompetitif \\
e. Adanya APMG yang aktif \\
f. Kualitas buah yang tinggi
\end{tabular}
Kelemahan (W)
a. Musim tidak menentu
b. Skala usaha
petani kecil
c. Kurangnya
pemasaran online
d. Teknologi pasca panen yang terbatas
e. Modal petani rendah
f. Biaya produksi tinggi

\begin{tabular}{|c|c|c|}
\hline Peluang (O) & Strategi SO & Strategi WO \\
\hline $\begin{array}{l}\text { a. Tren sosial konsumen } \\
\text { b. Permintaan konsumen } \\
\text { meningkat } \\
\text { c. Lembaga perkreditan } \\
\text { yang meningkat } \\
\text { d.. Tuntutan pemasaran } \\
\text { online yang masa } \\
\text { pandemi } \\
\text { e. kebijakan pemerintah } \\
\text { yang mendukung } \\
\text { f. Buah yang memiliki } \\
\text { keunikan }\end{array}$ & $\begin{array}{l}\text { Meluaskan kawasan } \\
\text { pengembangan dan } \\
\text { pemantapan wilayah } \\
\text { budidaya mangga klonal } 21 \\
\text { dengan penerapan prosedur } \\
\text { pertanaman serta pengolahan } \\
\text { yang ketat melalui } \\
\text { koordinasi di tiap anggota } \\
\text { Gapoktan S1, S2, S3, S6, } \\
\text { O2,O4) }\end{array}$ & $\begin{array}{l}\text { Melakukan } \\
\text { pengembangan } \\
\text { season guna memenuhi } \\
\text { permintaan pasar serta } \\
\text { meningkatkan ekonomi } \\
\text { petani. Bekerja sama } \\
\text { dengan lembaga } \\
\text { perkreditan guna } \\
\text { menambah modal petani } \\
\text { yang masih kurang W1, } \\
\mathrm{O} 2, \mathrm{O} 3, \mathrm{O} 6)\end{array}$ \\
\hline Ancaman $(\mathrm{T})$ & $\begin{array}{c}\text { Strategi ST } \\
\end{array}$ & Strategi WT \\
\hline $\begin{array}{ll}\text { a. } & \text { Hama dan penyakit } \\
\text { b. } & \begin{array}{l}\text { Permintaan pasar } \\
\text { yang melampaui }\end{array} \\
\text { batas maksimum } \\
\text { c. } & \text { Pesaing sejenis } \\
\text { penjual mangga } \\
\text { varietas lain } \\
\text { d. } & \text { Penipuan yang }\end{array}$ & $\begin{array}{l}\text { Memberdayakan petani guna } \\
\text { menanggulangi ancaman } \\
\text { dalam budidaya serta } \\
\text { mengajak wanita tani } \\
\text { berkontribusi mengolah } \\
\text { mangga klonal } 21 \text { guna } \\
\text { menambah nilai jual serta } \\
\text { menghindari pesaing sejenis }\end{array}$ & $\begin{array}{l}\text { Melakukan } \\
\text { pengembangan } \\
\text { pengolahan pasca panen } \\
\text { serta mematenkan merk } \\
\text { guna menghindari } \\
\text { pemalsuan nama mangga } \\
\text { klonal } 21 \text { dan melakukan } \\
\text { promosi di media sosial }\end{array}$ \\
\hline
\end{tabular}




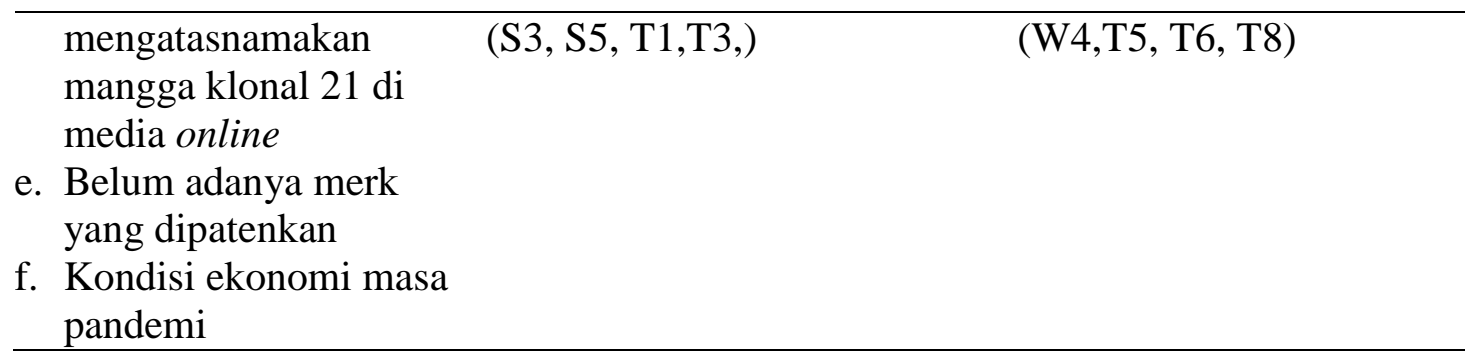

Sumber: Data Primer Diolah, 2020

Penentuan Prioritas Strategi Pemasaran Mangga Klonal 21

Tabel 5. Matriks QSPM

\begin{tabular}{|c|c|c|c|c|c|c|c|c|c|c|}
\hline \multirow{2}{*}{$\begin{array}{l}\mathrm{N} \\
\mathrm{o} \\
\mathrm{K}\end{array}$} & Faktor Utama & \multirow{3}{*}{$\begin{array}{l}\text { Bobot } \\
0.09\end{array}$} & \multicolumn{2}{|c|}{ Strategi 1} & \multicolumn{2}{|c|}{ Strategi 2} & \multicolumn{2}{|c|}{ Strategi 3} & \multicolumn{2}{|c|}{ Strategi 4} \\
\hline & Kekuatan & & AS & TAS & AS & TAS & AS & TAS & AS & TAS \\
\hline 1. & $\begin{array}{l}\text { Produk unggulan Kabupaten } \\
\text { Pasuruan }\end{array}$ & & 4 & 0.36 & 4 & 0.36 & 4 & 0.36 & 4 & 0.36 \\
\hline 2. & $\begin{array}{l}\text { Lokasi pembudidayaan } \\
\text { sesuai agroklimat }\end{array}$ & 0.09 & 4 & 0.36 & 4 & 0.36 & 3 & 0.27 & 1 & 0.09 \\
\hline 3. & SDM petani terampil & 0.1 & 3 & 0.3 & 3 & 0.3 & 4 & 0.4 & 4 & 0.4 \\
\hline 4. & $\begin{array}{l}\text { Harga mangga lebih } \\
\text { kompetitif }\end{array}$ & 0.09 & 3 & 0.27 & 4 & 0.36 & 1 & 0.09 & 1 & 0.09 \\
\hline 5 & Kelembagaan aktif & 0.09 & 3 & 0.27 & 4 & 0.36 & 4 & 0.36 & 4 & 0.36 \\
\hline 6. & $\begin{array}{l}\text { Kualitas produk dapat } \\
\text { bersaing }\end{array}$ & 0.09 & 4 & 0.36 & 4 & 0.36 & 3 & 0.27 & 4 & 0.36 \\
\hline \multicolumn{11}{|c|}{ Kelemahan } \\
\hline 1. & Musim tidak menentu & 0.07 & 1 & 0.07 & 4 & 0.28 & 4 & 0.28 & 3 & 0.21 \\
\hline 2. & Skala usaha petani kecil & 0.07 & 4 & 0.28 & 3 & 0.21 & 4 & 0.28 & 4 & 0.28 \\
\hline 3. & Kurangya pemasaran online & 0.08 & 1 & 0.08 & 3 & 0.24 & 1 & 0.08 & 4 & 0.32 \\
\hline 4. & $\begin{array}{l}\text { Teknologi pasca panen } \\
\text { terbatas }\end{array}$ & 0.08 & 1 & 0.08 & 1 & 0.08 & 3 & 0.24 & 2 & 0.16 \\
\hline 5. & Modal petani masih rendah & 0.08 & 3 & 0.24 & 4 & 0.32 & 4 & 0.32 & 3 & 0.24 \\
\hline 6. & Biaya Produksi tinggi & 0.07 & 1 & 0.07 & 4 & 0.28 & 3 & 0.21 & 1 & 0.07 \\
\hline \multicolumn{11}{|c|}{ Peluang } \\
\hline 1. & Tren sosial konsumen & 0.07 & & - & & - & & - & & - \\
\hline 2. & $\begin{array}{l}\text { Permintaan konsumen } \\
\text { meningkat melalui media } \\
\text { online }\end{array}$ & 0.08 & 4 & 0.32 & 4 & 0.32 & 4 & 0.32 & 2 & 0.16 \\
\hline 3. & $\begin{array}{l}\text { Lembaga perkreditan yang } \\
\text { meningkat }\end{array}$ & 0.08 & 1 & 0.08 & 4 & 0.32 & 2 & 0.16 & 1 & 0.08 \\
\hline 4. & $\begin{array}{l}\text { Tuntutan pemasaran online } \\
\text { masa pandemi }\end{array}$ & 0.09 & 4 & 0.36 & 4 & 0.36 & 3 & 0.27 & 4 & 0.36 \\
\hline 5. & $\begin{array}{l}\text { Kebijakan pemerintah yang } \\
\text { mendukung }\end{array}$ & 0.09 & 4 & 0.36 & 1 & 0.09 & 1 & 0.09 & 3 & 0.09 \\
\hline 6. & $\begin{array}{l}\text { Produk yang jarang } \\
\text { dijumpai }\end{array}$ & 0.09 & 4 & 0.36 & 4 & 0.36 & 3 & 0.27 & 4 & 0.36 \\
\hline \multicolumn{11}{|c|}{ Ancaman } \\
\hline 1. & Hama dan penyakit & 0.07 & 1 & 0.07 & 2 & 0.14 & 4 & 0.28 & 1 & 0.07 \\
\hline 2. & $\begin{array}{l}\text { Permintaan pasar yang } \\
\text { melampaui batas maksimum }\end{array}$ & 0.09 & 4 & 0.36 & 4 & 0.36 & 1 & 0.09 & 4 & 0.36 \\
\hline 3. & $\begin{array}{l}\text { Pesaing sejenis penjual } \\
\text { mangga varietas lain }\end{array}$ & 0.09 & 4 & 0.36 & 4 & 0.36 & 4 & 0.36 & 4 & 0.36 \\
\hline 4. & $\begin{array}{l}\text { Penipuan yang } \\
\text { mengatasnamakan mangga } \\
\text { klonal } 21 \text { di media online }\end{array}$ & 0.09 & 1 & 0.09 & 2 & 0.18 & 3 & 0.27 & 4 & 0.36 \\
\hline
\end{tabular}




\begin{tabular}{llllllllll} 
5. $\begin{array}{l}\text { Belum adanya merk yang } \\
\text { dipatenkan }\end{array}$ & 0.08 & 1 & 0.08 & 3 & 0.24 & 1 & 0.08 & 4 & 0.32 \\
6. $\begin{array}{l}\text { Kondisi ekonomi masa } \\
\text { pandemi }\end{array}$ & 0.08 & 1 & 0.08 & 1 & 0.08 & 1 & 0.08 & 1 & 0.08 \\
\hline Total & & $\mathbf{5 . 2 6}$ & $\mathbf{6 . 3 2}$ & $\mathbf{5 . 4 6}$ & $\mathbf{5 . 5 4}$ \\
\hline
\end{tabular}

Sumber: Data primer Diolah, 2020

Berdasarkan hasil pengolahan
strategi alternative strategi 2 yakni melakukan pengembangan off season guna memenuhi permintaan pasar serta meningkatkan ekonomi petani. Bekerja sama dengan lembaga perkreditan guna menambah modal petani yang masih kurang dengan jumlah skor sebesar 6,32 .

\section{IV.PENUTUP}

\subsection{Kesimpulan}

Kesimpulan penelitian diatas diperoleh posisi pemasaran mangga klonal 21 terletak pada kaudran II dimana menerapkan strategi diversifikasi. Strategi diversifikasi dilakukan dengan pengembangan produk olahan kepada konsumen guna menghindari pembusukan saat di perjalanan dan menjadi terobosan baru dalam oleh - oleh selain dari buah segarnya.

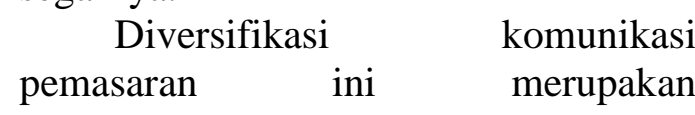
pengembangan pemasaran media sosial dengan mempromosikan mangga klonal 21 semenarik mungkin sehingga konsumen tertarik dalam membeli mangga klonal 21. Alternatif strategi pemasaran berdasarkan perhitungan QSPM guna meningkatkan jangkaun pemasaran maka strategi yang digunakan berupa melakukan pengembangan secara off season guna memenuhi permintaan pasar serta meningkatkan ekonomi petani dan bekerja sama dengan lembaga perkreditan guna menambah modal petani yang masih kurang dan pengembangan produk olahan dengan mengedepankan kualitas SDM berupa penggunaan teknologi guna menunjang kualitas dan kuantitas mangga klonal 21.

\subsection{Saran}

Sebaiknya pemasaran mangga klonal 21 menerapkan strategi intensif dimana mencakup pengembangan pasar, penetrasi pasar, pengembangan produk serta strategi integrasi yang digunakan berupa integrasi ke depan, integrasi belakang, dan integrasi horizontal. Alternatif strategi yang dapat digunakan untuk memenuhi permintaan pasar yakni dengan cara melakukan pengembangan secara off season guna memenuhi permintaan pasar.

\section{DAFTAR PUSTAKA}

Amarala, A. N. G., Supardi, S., \& Harisudin, M. 2020. Strategi Pemasaran Produk "Tempe Samodra" Kelurahan Mojosongo, Kecamatan Jebres, Kota Surakarta. Agriecobis : Journal of Agricultural Socioeconomics and Business, 3(1), 08.

Asrina, \& Martina. 2017. Strategi Pemasaran Usaha Kerupuk Tempe di Desa Blang Geulanggang Kecamatan Peusangan Kabupaten Bireuen (Studi Kasus: Usaha Kerupuk Tempe Ibu Yusnita). S. Pertanian, 1(1), 48-62.

Azizah, M. N., Rasmikayati, E., \& Saefudin, B. R. 2019. Perilaku Budidaya Petani Mangga Dikaitkan dengan Lembaga Pemasarannya di Kecamatan 
Greged Kabupaten Cirebon. Jurnal Ilmiah Mahasiswa Agroinfo Galuh, 5(1), 987.

Heridiansyah, J. 2012. Pengaruh Advertising Terhadap Pembentukan Brand Awareness Serta Dampaknya Pada Keputusan Pembelian Produk Kecap Pedas ABC. Jurnal STIE Semarang, 4(2), 53-73.

Mujahid, A., Isharyani, M. E., \& Widada, D. 2018. Analisis Strategi Pemasaran Mengunakan Metode Quantitative Strategic Planning Matrik (QSPM) Studi Kasus : Borneo Project. Jurnal Rekayasa Sistem Industri, 7(2),.111-118

Mukhsin, R., Mappigau, P., \& Tenriawaru, A. N. (2017). Pengaruh Orientasi Kewirausahaan Terhadap Daya Tahan Hidup Usaha Di Kota Makassar. Jurnal Analisis, 6(2), 188-193.

Nur Aziz, T., Rizal, M., Arifianti, R., \& Husna, A. (2021). Strategi Marketing Pada CV. Kembar Jaya Kreatif Dengan Memanfaatkan Analisis Swot Serta QSPM. Bahtera Inovasi, 4(2), 128-138.

Octaviani, R., Anantanyu, S., \& Ihsaniyati, H. 2018. Analisis Keefektifan Iklan Sebagai Strategi Komunikasi Pemasaran Produk Jenang CV. Mubarook food Cipta Delicia Menggunakan EPIC Model. SEPA: Jurnal Sosial Ekonomi Pertanian Dan Agribisnis, 14(2), 114.

Oktavianto, Y., Sunaryo, \& Suryanto, A. 2015. Kabupaten Kediri Characterization of plant mango (Mangifera indica l.) Cantek , ireng, empok, jempol. Jurnal Produksi Tanaman, Volume 3(2), 91-97.
Prayogo, A. 2015. Komunikasi Pemasaran Usaha Kuliner Dalam Menghadapi Persaingan. Ilmu Komunikasi, 1, 5.

Raymond Mc.Leod. 2017. Jurnal Ilmu Komunikasi (KAREBA). 05(2), 428.

Sawitri, N. 2018. (Studi Kasus Penggilingan Jaya Bakti). 7(2), 1224.

Suandani, n., Darmawan, d., \& Dewi, i. 2016. Strategi Pemasaran Kacang Asin Kelompok Wanita Tani Sinar Rejeki Desa Jumpai, Kecamatan Klungkung, Kabupaten Klungkung. E-Journal Agribisnis Dan Agrowisata (Journal of Agribusiness and Agritourism), 5(4), 732-741.

Sugianto, C. A., \& Hongdiyanto, C. (2017). Perumusan Strategi Pemasaran Menggunakan Metode QSPM Pada Bisnis Sambal Noesantara. Jurnal Manajemen Dan Start-up Bisnis, 2(1), 106115.

Utami, H. N., \& Firdaus, I. F. A. (2018). Ecodemica. Jurnal Ecodemica: Jurnal Ekonomi, Manajemen, Dan Bisnis, 2(1), 136-146.

Wibowo, D. H., Arifin, Z., \& Sunarti. (2015). Strategi dan Program Pemasaran. Jurnal Administrasi Bisnis (JAB), 29(1), 59-66.

Wira'artha, I. C., P, N. N., \& N, P. E. (2017). Analisis Pengambilan Keputusan dan Strategi Pemasaran Di Tingkat Kebutuhan Kelor Indonesia (Kasus Agribisnis : Kelor Madura). Jurnal Sains Dan Seni ITS, 6(2). 